\title{
Erratum to: Prevalence of Psychotropic Drug Use in Adults with Intellectual Disability: Positive and Negative Findings from a Large Scale Study
}

\author{
John A. Tsiouris $\cdot$ Soh-Yule Kim $\cdot$ W. Ted Brown • \\ Jill Pettinger · Ira L. Cohen
}

Published online: 24 August 2012

(C) Springer Science+Business Media, LLC 2012

\section{Erratum to: J Autism Dev Disord}

DOI 10.1007/s10803-012-1617-6

Please note the following corrections to this article:

In the abstract (line 6):

"Six percent received typical, $6 \%$ received typical, while $39 \%$ received atypical antipsychotics."

Instead should say:

"Six percent received typical, while $39 \%$ received atypical antipsychotics."

In Table 8, under the column heading " 3 ", all of the " $<$ " signs should not be there.
The numbers:

$(<0.3)$

$(<0.2)$

$(<0.2)$

$(<0.1)$

$(<0.3)$

Instead should say:

$(0.3)$

$(0.2)$

$(0.2)$

$(0.1)$

$(0.3)$

The online version of the original article can be found under doi:10.1007/s10803-012-1617-6.

\section{J. A. Tsiouris}

George A. Jervis Clinic, New York State Institute for Basic

Research in Developmental Disabilities, 1050 Forest Hill Rd.,

Staten Island, NY 10314, USA

S.-Y. Kim · I. L. Cohen ( $₫)$

Department of Psychology, New York State Institute for Basic

Research in Developmental Disabilities, 1050 Forest Hill Rd.,

Staten Island, NY 10314, USA

e-mail: ira.cohen@opwdd.ny.gov

\section{W. T. Brown}

Department of Human Genetics, New York State Institute for Basic Research in Developmental Disabilities,

1050 Forest Hill Rd., Staten Island, NY 10314, USA

J. Pettinger

OPWDD Statewide Services, Albany, NY, USA 